\begin{tabular}{|c|c|}
\hline Title & Optimum Exploration for the Self-Ordering of A nodic Porous A lumina Formed via Selenic A cid A nodizing \\
\hline Author(s) & A kiya, Shunta; Kikuchi, T atsuya; Natsui, Shungo; Suzuki, Ryosuke $O$. \\
\hline Citation & $\begin{array}{l}\text { Journal of The Electrochemical Society, 162(10), E244-E250 } \\
\text { https://doi.org/10.1149/2.0391510jes }\end{array}$ \\
\hline Issue Date & 2015 \\
\hline Doc URL & http://hdl .handle.net/2115/59570 \\
\hline Rights & $\begin{array}{l}\text { (O) The Electrochemical Society, Inc. 2015. All rights reserved. Except as provided under U.S. copyright law, this work } \\
\text { may not be reproduced, resold, distributed, or modified without the express permission of The Electrochemical Society } \\
\text { (ECS). The archival version of this work was published in ECS Transactions, V olume 162, Issue 10, pp. E244 E250, } \\
2015 \text {. }\end{array}$ \\
\hline Rights(URL) & http://creativecommons.org/icenses/by-nc-nd/4.0/ \\
\hline Type & article \\
\hline File Information & Selenic3.pdf \\
\hline
\end{tabular}

Instructions for use 


\title{
Optimum Exploration for the Self-Ordering of Anodic Porous Alumina Formed via Selenic Acid Anodizing
}

\author{
Shunta Akiya, Tatsuya Kikuchi, ${ }^{\mathrm{z}}$ Shungo Natsui, and Ryosuke O. Suzuki \\ Faculty of Engineering, Hokkaido University, Sapporo, Hokkaido 060-8628, Japan
}

\begin{abstract}
Improvements of the regularity of the arrangement of anodic porous alumina formed by selenic acid anodizing were investigated under various operating conditions. The oxide burning voltage increased with the stirring rate of the selenic acid solution, and the high applied voltage without oxide burning was achieved by vigorously stirring the solution. The regularity of the porous alumina was improved as the anodizing time and surface flatness increased. Conversely, the purity of the 99.5-99.9999 wt\% aluminum specimens without second phases of metals and metallic compounds was not affected by the regularity of the porous alumina formed by selenic acid anodizing. The porous alumina was also self-ordered on/around a defect, such as a grain boundary, under self-ordering high voltage anodizing conditions. A highly ordered cell arrangement measuring $111 \mathrm{~nm}$ in diameter was successfully fabricated over the whole aluminum surface by selenic acid anodizing using a $99.999 \mathrm{wt} \%$ aluminum plate at $273 \mathrm{~K}$ and $46 \mathrm{~V}$ for $24 \mathrm{~h}$ under vigorous stirring conditions.

(C) The Author(s) 2015. Published by ECS. This is an open access article distributed under the terms of the Creative Commons Attribution Non-Commercial No Derivatives 4.0 License (CC BY-NC-ND, http://creativecommons.org/licenses/by-nc-nd/4.0/), which permits non-commercial reuse, distribution, and reproduction in any medium, provided the original work is not changed in any way and is properly cited. For permission for commercial reuse, please email: oa@electrochem.org. [DOI: 10.1149/2.0391510jes] All rights reserved.
\end{abstract}

Manuscript submitted June 3, 2015; revised manuscript received July 8, 2015. Published July 28, 2015.

Anodic porous alumina with numerous nanoscale pores has been widely used as a template and membrane in nanofabrication, such as optical applications, ${ }^{1-3}$ sensors, ${ }^{4-6}$ electronic devices, ${ }^{7-9}$ and other novel nanotechnologies. ${ }^{10-13}$ In nanofabrication using porous alumina, it is important to fabricate and use "highly ordered" porous alumina with an ideal honeycomb cell arrangement because of the improvement of their optical, sensing, and electronic properties. Highly ordered porous alumina can typically be obtained via aluminum anodizing in several acidic electrolyte solutions under the appropriate electrochemical conditions. ${ }^{14-16}$ Sulfuric, oxalic, and phosphoric acids are well known major self-ordering electrolytes for anodizing aluminum and are widely used for the fabrication of ordered porous alumina films. ${ }^{17}$ The self-ordering behavior of the porous alumina during anodizing in these three electrolyte solutions has been carefully studied by high resolution scanning electron microscopy (SEM) observations and quantitative arrangement analysis based on fast Fourier transform (FFT) ${ }^{18-20}$ The periodicity of the self-ordered porous alumina (i.e., the periodicity is determined as cell diameter or interpore distance) was measured as approximately $50-60 \mathrm{~nm}$ at $19-25 \mathrm{~V}$ of applied voltage for sulfuric acid, $100 \mathrm{~nm}$ at $40 \mathrm{~V}$ for oxalic acid, and $405-500 \mathrm{~nm}$ at $160-195 \mathrm{~V}$ for phosphoric acid. ${ }^{15,21}$ However, because the cell diameters obtained via typical anodizing are limited to the narrow nanoscale range as described above, the location of novel additional electrolytes is required for various nanofabrications using ordered porous alumina films.

From this background, several research groups have studied the electrochemical behavior during aluminum anodizing in various unknown electrolyte solutions. ${ }^{22-35}$ In addition, the mixture of the electrolyte solutions has also been investigated to control the anodizing voltage and corresponding cell diameter. ${ }^{36-42}$ Very recently, we reported novel self-ordering electrolytes (selenic acid $\left(\mathrm{H}_{2} \mathrm{SeO}_{4}\right)$, etidronic acid $\left(\mathrm{CH}_{3} \mathrm{C}(\mathrm{OH})\left[\mathrm{PO}(\mathrm{OH})_{2}\right]_{2}\right.$, and phosphonoacetic acid $\left.(\mathrm{HO})_{2} \mathrm{P}(\mathrm{O}) \mathrm{CH}_{2} \mathrm{COOH}\right)$ for the fabrication of porous alumina with a different periodicity. ${ }^{43-47}$ These electrolytes exhibit a novel periodicity measuring 95-112 $\mathrm{nm}$ at $42-48 \mathrm{~V}, 530-670 \mathrm{~nm}$ at $210-270 \mathrm{~V}$, $500-550 \mathrm{~nm}$ at $205-225 \mathrm{~V}$, respectively. Typically, the regularity of the porous alumina formed by anodizing is strongly affected by various operating factors, including electrochemical conditions and the micro-/nanostructure of the starting aluminum substrate. ${ }^{23}$ However, the details of the self-ordering behavior of the porous alumina formed via anodizing in these novel electrolyte solutions have not yet been reported.

${ }^{\text {z} E-m a i l: ~ k i k u @ e n g . h o k u d a i . a c . j p ~}$
In the present investigation, we describe the effect of various operating conditions on the self-ordering behavior of the porous alumina formed by anodizing in a selenic acid solution. In addition, we fabricated a highly ordered anodic porous alumina with an ideal cell arrangement via selenic acid anodizing based on the optimum operating conditions obtained in the present investigation. The results for self-ordering will be valuable in anodizing using other self-ordering electrolytes.

\section{Experimental}

Starting aluminum specimens and their pretreatment.- The following five types of aluminum plates and foils with different purities were used as the anodizing specimen: a) $99.9999 \mathrm{wt} \%(6 \mathrm{~N})$ aluminum, $0.25 \mathrm{~mm}$ thick, impurities: $\mathrm{C}<2 \mathrm{ppm}, \mathrm{O}<1 \mathrm{ppm}, \mathrm{N}<1$ ppm (Alfa Aesar, USA); b) $99.999 \mathrm{wt} \%$ (5N) aluminum, 0.25-1.0 mm thick, impurities: $\mathrm{Mg} 1.2 \mathrm{ppm}, \mathrm{Si} 0.8 \mathrm{ppm}, \mathrm{Cu} 0.3 \mathrm{ppm}, \mathrm{Fe} 0.3 \mathrm{ppm}$ (GoodFellow, UK); c) $99.99 \mathrm{wt} \%$ (4N) aluminum, $0.11 \mathrm{~mm}$ thick, impurities: Cu 57 ppm, Fe 10 ppm, Si 9 ppm (Showa Aluminum, Japan); d) $99.5 \mathrm{wt} \%$ aluminum, $0.10 \mathrm{~mm}$ thick, impurities: $\mathrm{Fe}<4000 \mathrm{ppm}$, $\mathrm{Si}<3000$ ppm, $\mathrm{Zn}<1000$ ppm, $\mathrm{Cu}<500$ ppm, $\mathrm{Mn}<500$ ppm (GoodFellow); and e) $94.5 \mathrm{wt} \%$ aluminum, $3.0 \mathrm{~mm}$ thick, impurities: $\mathrm{Cu} 5 \mathrm{wt} \%$, Fe 0.3 wt\%, Si 0.2 wt\% (Showa Denko, Japan).

Several aluminum specimens were mechanically polished with a $\mathrm{SiC}$ waterproof abrasive paper of $\# 600$ before electropolishing. All of the specimens were ultrasonically degreased in an ethanol solution for $10 \mathrm{~min}$ and were then electropolished in a $13.6 \mathrm{M} \mathrm{CH}_{3} \mathrm{COOH} / 2.56 \mathrm{M}$ $\mathrm{HClO}_{4}\left(78 \mathrm{vol} \% \mathrm{CH}_{3} \mathrm{COOH} / 22 \mathrm{vol} \% 70 \%-\mathrm{HClO}_{4}\right)$ mixture at a constant voltage of $28 \mathrm{~V}$ for $1-10 \mathrm{~min}$. To obtain a smoother aluminum surface, the following additional pretreatments, including barrier oxide formation and subsequent oxide dissolution, were carried out: ${ }^{48}$ the electropolished specimens were anodized in a $0.5 \mathrm{M} \mathrm{H}_{3} \mathrm{BO}_{3} / 0.05$ $\mathrm{M} \mathrm{Na}_{2} \mathrm{~B}_{4} \mathrm{O}_{7}$ mixture solution $(\mathrm{T}=293 \mathrm{~K})$ at a constant current density of $\mathrm{j}=2.5 \mathrm{Am}^{-2}$ up to $\mathrm{U}=100 \mathrm{~V}$ to form a barrier anodic oxide film on the aluminum substrate and then were immersed in a $0.2 \mathrm{M}$ $\mathrm{CrO}_{3} / 0.51 \mathrm{M} \mathrm{H}_{3} \mathrm{PO}_{4}$ solution $(\mathrm{T}=353 \mathrm{~K}$ ) to selectively dissolve the barrier oxide film and expose the ultra-smooth surface.

Selenic acid anodizing. - The pretreated aluminum specimens were immersed in a $3.0 \mathrm{M}$ selenic acid solution (Kanto Chemical, Japan, $\mathrm{T}=273 \mathrm{~K}, 150 \mathrm{~mL}$ ) and were anodized under a) a linear voltage sweep $\left(0.1 \mathrm{~V} \mathrm{~s}^{-1}\right)$ and $\left.\mathrm{b}\right)$ constant voltage $(\mathrm{U}=46 \mathrm{~V})$ conditions using a direct current power supply (PWR-400H, Kikusui, Japan) connected to a computer. At the low temperature of $273 \mathrm{~K}$, selenic acid anodizing is an effective way to form a self-ordered anodic porous 
alumina without burning. ${ }^{43}$ The inner diameter of the electrochemical cell used for anodizing was $55 \mathrm{~mm}$, and the selenic acid solution was stirred at $\mathrm{v}=0-814 \mathrm{rpm}$ with a magnetic cross-head stirrer bar during anodizing. The stirring behavior of the solution in the electrochemical cell at each stirring rate was recorded from the side by a digital camera. A glassy carbon plate (Tokai Carbon, Japan, $1 \mathrm{~mm}$ thick) was used as the counter electrode. The current density during the linear voltage sweep and constant voltage anodizing were measured using a digital multi-meter (DMM4040, Tektronix, Japan).

After selenic acid anodizing, the anodized specimens were immersed in a $\mathrm{CrO}_{3} / \mathrm{H}_{3} \mathrm{PO}_{4}$ solution to selectively dissolve the porous alumina formed on the aluminum substrate. Therefore, the nanostructured aluminum surface, with an aluminum nanodimple array corresponding to the shape of the bottom of the porous alumina, was exposed to the surface. ${ }^{44}$ The nanostructured aluminum surface was used for the quantitative analysis of the regularity of the porous alumina.

The surface and the cross-section of the aluminum specimens were examined by a field-emission SEM (JSM-6500F and JIB4600F/HKD, JEOL, Japan) and atomic force microscopy (AFM, Nanocute, Hitachi, Japan). To observe the cross-section, the anodized specimens were embedded in an epoxy resin and polished mechanically.

\section{Results and Discussion}

Effect of stirring the solution on the oxide burning phenomenon.During typical anodizing, the self-ordering of the anodic porous alumina can be achieved under the maximum voltage required to induce a high current density without the oxide burning phenomenon. ${ }^{23}$ To avoid oxide burning, the electrolyte solution should be stirred vigorously at a low temperature during anodizing and the Joule heat generated by anodizing should be efficiently removed from the specimens. Therefore, the effect of stirring the solution on the burning phenomenon during selenic acid anodizing was investigated first.

Figure 1 shows the appearance of the electrochemical anodizing cell at various stirring rates of the solution, from a) $v=0$ to e) 814 rpm. During stirring, a glassy carbon cathode was immersed at the center of the electrochemical cell, and an aluminum anode was set at the left side of the cell and parallel $(15 \mathrm{~mm})$ to the cathode without voltage being applied (Fig. 1a). When the solution was stirred with a magnetic stirrer bar at $\mathrm{v}=257 \mathrm{rpm}$ (Fig. 1b), the liquid surface at the center position fell slightly toward to the bottom because of the rotation of the solution and a small whorl was formed on the surface of the solution. The solution whorl gradually became larger with the stirring rate of the solution (Figs. 1c through 1e), and an extremely large whorl was observed in the solution under vigorously stirring at $\mathrm{v}=814 \mathrm{rpm}$ (Fig. 1e). The electropolished aluminum specimens $(99.999 \mathrm{wt} \%)$ were anodized in selenic acid solution under these five sets of stirring conditions.

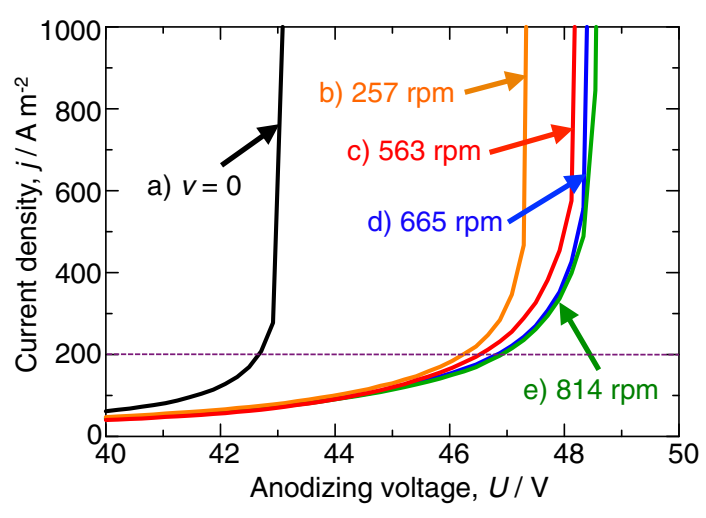

Figure 2. Changes in the current density, j, with anodizing voltage, U, during a linear voltage sweep $\left(0.1 \mathrm{~V} \mathrm{~s}^{-1}\right)$ in a $3.0 \mathrm{M}$ selenic acid solution at $273 \mathrm{~K}$ under various stirring conditions of $\mathrm{v}=0-814 \mathrm{rpm}$, described in Fig. 1.

Figure 2 shows changes in the current density, $\mathrm{j}$, with applied voltage, $\mathrm{U}$, using a linear voltage sweep method (voltage scan rate: 0.1 $\left.\mathrm{V} \mathrm{s}^{-1}\right)$ in a $3.0 \mathrm{M}$ selenic acid solution $(\mathrm{T}=273 \mathrm{~K})$ under various stirring conditions. Without stirring the solution (Fig. 2a), the current density gradually increased with the applied voltage and then rapidly increased to a value above $1000 \mathrm{Am}^{-2}$ at $\mathrm{U}=43 \mathrm{~V}$. Oxygen gas was vigorously generated from the aluminum specimen with the rapid increase and a non-uniform anodic oxide was formed on the aluminum surface. This "oxide burning" is observed due to the large Joule heat generation by the high current density and the subsequent high electric field applied in a localized region. ${ }^{49,50}$ As the stirring rate increased to 257 (Fig. 2b) and $563 \mathrm{rpm}$ (Fig. 2c), the burning voltages became considerably larger (4-5 V) than the voltages measured by anodizing without stirring. This burning voltage increase is due to the efficient removal of the Joule heat generated from the aluminum specimen by strong stirring of the solution, as described in Fig. 1. The burning voltage showed almost the same value of approximately $48 \mathrm{~V}$ at $\mathrm{v}=665$ (Fig. 2d) and $814 \mathrm{rpm}$ (Fig. 2e), although the burning voltage increased very slightly with the rate of stirring. Therefore, the excessive stirring of the solution does not contribute to the burning voltage increase. When the aluminum anode was set perpendicularly to the glassy carbon cathode (i.e., the aluminum specimen was rotated to $90^{\circ}$ from the parallel position, as described in Fig. 1a), similar burning voltages at each stirring rate were measured by selenic acid anodizing.

As described in Fig. 1 and Fig. 2, it is important to stir the electrolyte solutions vigorously to avoid oxide burning, although excess stirring of the solution causes a similar burning voltage. In the previous investigation, we found that highly ordered porous alumina could be successfully obtained via selenic acid anodizing under the most appropriate voltage of $46 \mathrm{~V} .{ }^{44}$ In addition, from experimental knowledge, it is difficult to operate at the high current density condition
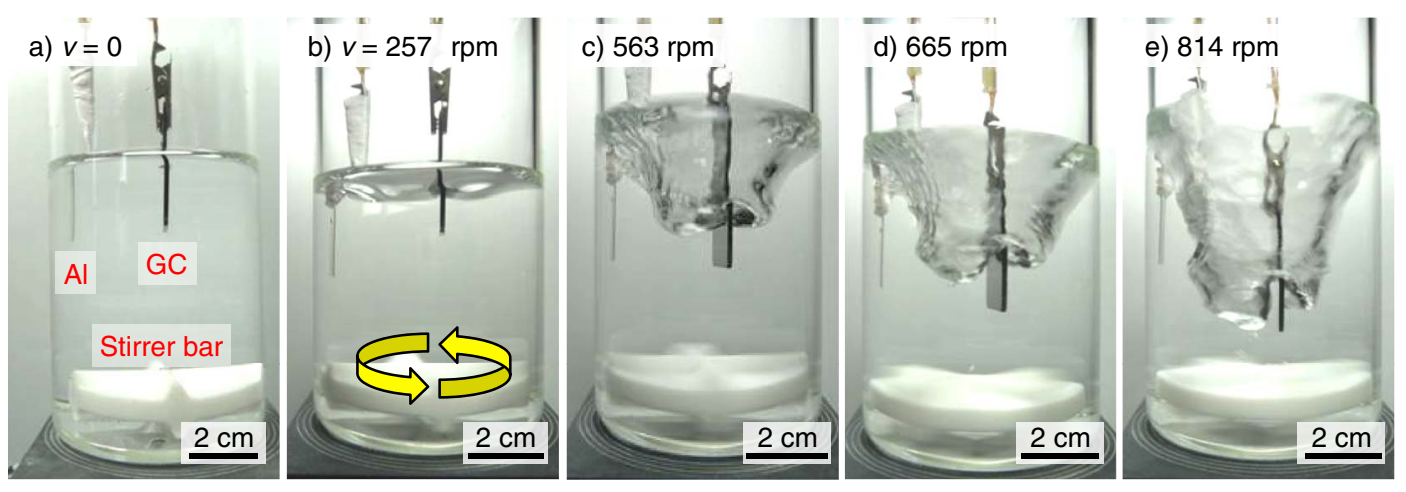

Figure 1. Video images of the electrochemical anodizing cell with an aluminum anode and a glassy carbon cathode under various stirring conditions at $\mathrm{v}=0-814$ rpm using a magnetic cross-head stirring bar. 


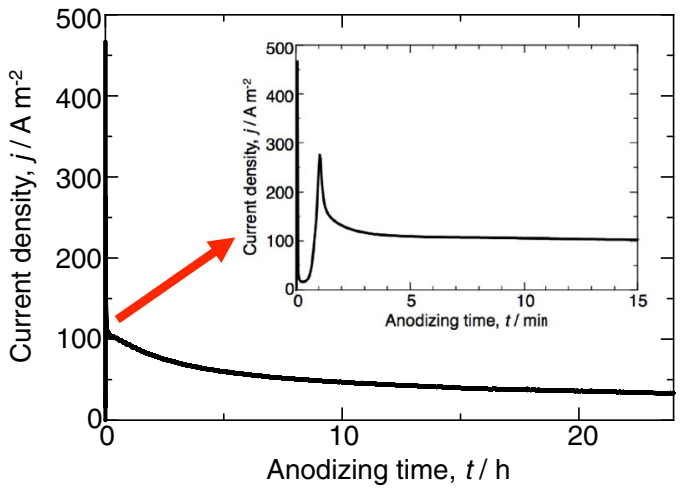

Figure 3. Change in the current density, $j$, with anodizing time, $t$, during selenic acid anodizing at a constant cell voltage of $\mathrm{U}=46 \mathrm{~V}$. The insert figure shows the current-time transient for the initial $15 \mathrm{~min}$.

of above $200 \mathrm{Am}^{-2}$ (dotted line in Fig. 2) for steady-state constant anodizing. Therefore, further anodizing in the next experiments was performed at $\mathrm{U}=46 \mathrm{~V}$ under the vigorous stirring condition of $\mathrm{v}$ $=563 \mathrm{rpm}$. In this vigorous stirring condition, the contact area between the electrode and selenic acid solution may be little changing during anodizing. However, relative stable current densities without an oscillation were measured during selenic acid anodizing under the vigorous stirring condition. On the other hand, anodizing must be carried out in an improved electrochemical cell without whorl formation for large-scale anodizing or industrial applications.

Effect of anodizing time on the self-ordering behavior- - Figure 3 shows the change in the current density, $\mathrm{j}$, with anodizing time, $\mathrm{t}$, at a constant anodizing voltage of $\mathrm{U}=46 \mathrm{~V}$ in a $3.0 \mathrm{M}$ selenic acid solution $(\mathrm{T}=273 \mathrm{~K})$ under vigorous stirring conditions of $\mathrm{v}=563$ rpm. Before anodizing, $99.999 \mathrm{wt} \%$ aluminum specimen was electropolished for $5 \mathrm{~min}$ as a pretreatment. As the voltage was applied, the current density increased rapidly and then decreased to approximately $17 \mathrm{Am}^{-2}$ in the initial anodizing period of $20 \mathrm{~s}$ due to barrier oxide formation on the aluminum substrate. After the initial stage, the current density increased again to approximately $280 \mathrm{Am}^{-2}$ and then gradually decreased with anodizing time due to the initiation of nanopore formation in the anodic oxide and subsequent steady growth of the porous alumina. This current-time transient is typically measured by constant voltage anodizing for the fabrication of anodic porous alumina. ${ }^{15,51}$ To observe the regularity of porous alumina for each anodizing step, the interface between the porous alumina and the aluminum substrate (i.e., the bottom shape of the porous alumina) was exposed to the surface by the selective dissolution of the anodic oxide in the $\mathrm{CrO}_{3} / \mathrm{H}_{3} \mathrm{PO}_{4}$ solution.

SEM images of the exposed aluminum substrate after selenic acid anodizing for 5 min through $24 \mathrm{~h}$ are shown in Figure 4. For a) $\mathrm{t}$ $=5 \mathrm{~min}$, a disordered aluminum dimple array with different dimple diameters can be observed on the aluminum substrate due to the disordered nucleation of the nanopores in the initial stage of anodizing. The regularity of the porous alumina was clearly improved with an increase in the anodizing time (Fig. 4b through 4e), and a highly ordered dimple array with a diameter of approximately $110 \mathrm{~nm}$ was successfully formed via long-term anodizing $(t=24 \mathrm{~h})$. Typically, long-term anodizing in major electrolyte solutions under appropriate conditions results in the formation of ordered porous alumina with an ideal cell arrangement due to the rearrangement of each cell. ${ }^{14}$ Selenic acid anodizing also has the same self-ordering behavior as these typical electrolytes, and long-term anodizing in the selenic acid solution is the effective way of self-ordering. In the previous investigation, we found that anodic alumina formed via selenic acid anodizing consisted of amorphous $\mathrm{Al}_{2} \mathrm{O}_{3}$ containing selenate ion. ${ }^{43}$ Selenate ions are incorporated in anodic porous alumina during selenic acid anodizing.
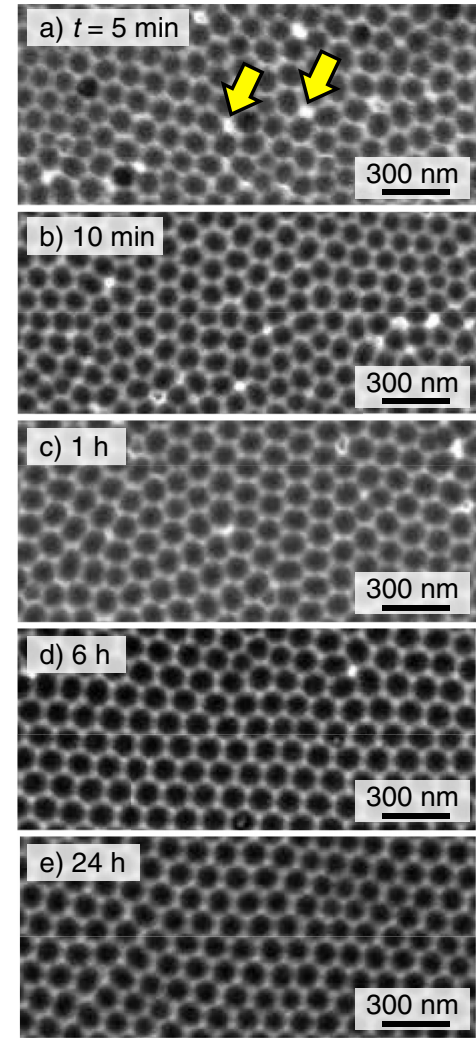

Figure 4. SEM images of the nanostructured aluminum surface formed by selenic acid anodizing for a) $5 \mathrm{~min}$ to e) $24 \mathrm{~h}$ and the subsequent selective oxide dissolution.

On the surface of the disordered aluminum dimple array (for example, shown in Fig. 4a), a large number of white spots can be observed at the interface between each of the dimples (indicated by yellow arrows). These spots are the fourth and fifth points formed by the incomplete self-ordering of the porous alumina. Figure 5a shows an SEM image of the fifth point on the disordered aluminum dimple array by the rotation of the specimen. A fine aluminum pillar measuring approximately $25 \mathrm{~nm}$ in diameter and $100 \mathrm{~nm}$ in length was formed at the junction of the fifth point. Such an aluminum pillar was typically observed on the disordered dimple array. ${ }^{27,52}$ Conversely, triple points without the pillar are clearly formed at apexes on the self-ordering dimple array (Fig. 5b). Therefore, a number of these fourth and fifth points exhibit the irregularity of the porous alumina formed via selenic acid anodizing. For the quantitative evaluation of the regularity of the porous alumina, the number of these defects was measured using SEM images of the nanostructured aluminum surface.

Figure $5 \mathrm{c}$ shows the change in the defect densities, n, with anodizing time, $t$, during the self-ordering of the porous alumina. The defect density after an anodizing time of 5 min was measured as approximately $\mathrm{n}=8.8 \mu \mathrm{m}^{-2}$. The density decreased with the increase in anodizing time and was measured to be the small value of $1.4 \mu \mathrm{m}^{-2}$ via the long-term anodizing period of $24 \mathrm{~h}$. Long-term anodizing is an extremely effective method of self-ordering for the porous alumina. The defect density formed at the interface during selenic acid anodizing under the self-ordering conditions can be expressed by the following equation:

$$
\mathrm{n}=3.8 \mathrm{t}^{-0.29}
$$

Considering this relationship, the following anodizing times are required for the fabrication of ordered porous alumina: $\mathrm{n}=1.0 \mu \mathrm{m}^{-2}$ for $\mathrm{t}=100 \mathrm{~h}$ (4.2 days) and $0.1 \mu \mathrm{m}^{-2}$ for $280,721 \mathrm{~h}$ (32 years). The length of the anodizing period required for the ordered porous alumina with near perfect cell arrangement is completely unrealistic. 


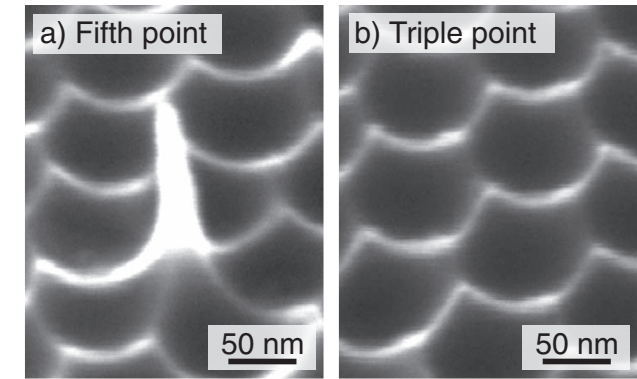

c)

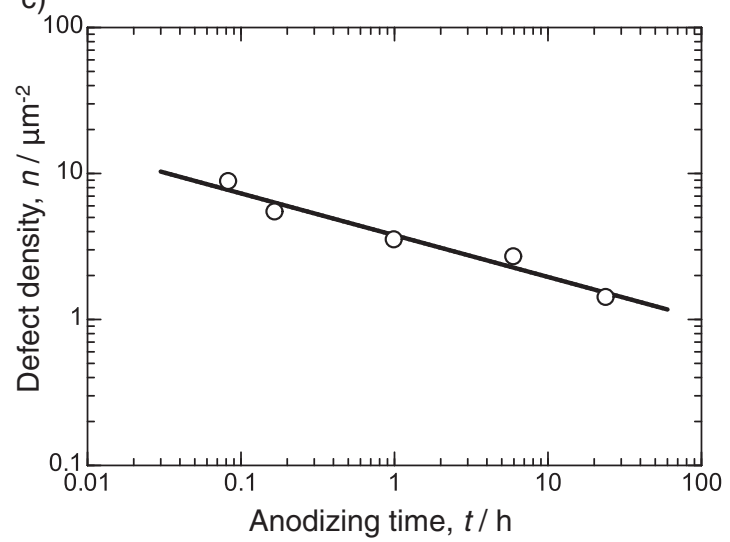

Figure 5. SEM images of a) the fifth and b) triple points of the aluminum dimple array formed via selenic acid anodizing at tilted viewing angles. c) Effect of anodizing time, $t$, on the defect density formed on the aluminum dimple array, $\mathrm{n}$, for selenic acid anodizing at the self-ordering voltage of $46 \mathrm{~V}$.

In the case of the formation of the ideal porous alumina, it is useful to combine nanoimprinting techniques with anodizing. ${ }^{53}$ However, such an irregularity of the porous alumina, measuring $1-10 \mu \mathrm{m}^{-2}$ in defect density, may be allowed in many nanoapplications. In addition, the near-ordered porous alumina shown in Fig. 4 e can easily be fabricated via the simple anodizing technique.

Effect of surface roughness on the self-ordering behavior- - Typically, the aluminum specimens were electropolished before anodizing because of the dissolution of a thin native oxide film formed on the aluminum substrate and also the smoothing of the surface. In this section, the effect of surface roughness on the self-ordering behavior during anodizing was investigated. An upper stage of Figure 6 shows SEM images of the surface of several pretreated aluminum specimens. The following pretreatments were carried out before selenic acid anodizing: a) mechanical polishing (MP) with a $\mathrm{SiC}$ paper of \#600, b) electropolishing (EP) in a $\mathrm{CH}_{3} \mathrm{COOH} / \mathrm{HClO}_{4}$ mixture for $1 \mathrm{~min}$ after mechanical polishing, c) EP for $5 \mathrm{~min}$, and d) EP for $10 \mathrm{~min}$. The mechanically polished aluminum substrate had an extremely uneven surface (Fig. 6a). As the mechanically polished specimen was electropolished in the $\mathrm{CH}_{3} \mathrm{COOH} / \mathrm{HClO}_{4}$ mixture for $1-10$ min (Figs. $6 \mathrm{~b}$ through $6 \mathrm{~d}$ ), the flatness of the aluminum surface clearly improved with the increase in the electropolishing time because electropolishing resulted in the microsmoothing of the aluminum surface with preferential electrochemical dissolution at the micro- and nano-scale convex part. ${ }^{54}$ From the AFM measurement, the calculated mean roughness of the electropolished aluminum surface for $10 \mathrm{~min}$ was measured as $1.19 \mathrm{~nm}$. This nanoscale roughness resulted in the formation of uneven nanostructure with periodic patterns formed on the aluminum surface after electropolishing, as reported previously. ${ }^{55}$ Therefore, it is difficult to obtain a smooth surface of an aluminum specimen with further electropolishing. To fabricate an ultra-smooth aluminum surface, post-treatments of the electropolished aluminum specimen were carried out. ${ }^{48}$ Figure $6 e$ shows the aluminum surface treated by forming a barrier oxide by anodizing in a neutral borate solution with subsequent selective oxide dissolution using an electropolished aluminum specimen for $10 \mathrm{~min}$ (EP/AP). The roughness of this post-treated aluminum specimen decreased to $0.88 \mathrm{~nm}$ by AFM observation. These five types of aluminum specimens with different roughnesses were anodized in a selenic acid solution at $46 \mathrm{~V}$ for $60 \mathrm{~min}$.

The bottom portion of Figure 6 shows SEM images of the nanostructured aluminum surface after selenic acid anodizing using several pretreated specimens. In the mechanically polished specimen (Fig. 6a), a disordered dimple array was distributed on the aluminum substrate, and the diameter of each of the dimples was quite different. The regularity of the dimple arrangement improved with the increase in electropolishing time (Figs. 6b through 6d), and an ordered dimple array was formed on the aluminum substrate using the electropolished specimen for $10 \mathrm{~min}$, although several defects were also observed on the surface. In the EP/AP specimen (Fig. 6e), a well-ordered dimple array with a cell arrangement similar to Fig. 6d was formed on the aluminum substrate.

A change in the defect densities, $n$, with pretreated electropolishing time, $t$, during selenic acid anodizing is shown in Figure 7. The defect density using the electropolished specimen for $1 \mathrm{~min}$ was measured as $8.7 \mu \mathrm{m}^{-2}$ due to the incomplete electrochemical polishing on the aluminum surface. Additional electropolishing caused a decrease of the defect density, and the defect density formed by an electropolishing a) MP
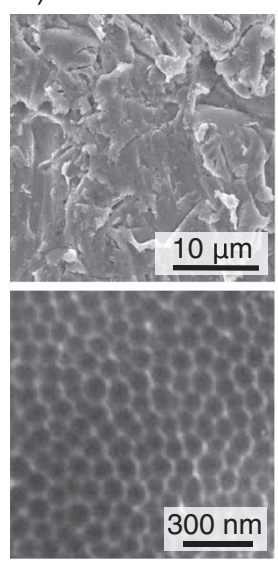

b) EP for $1 \mathrm{~min}$
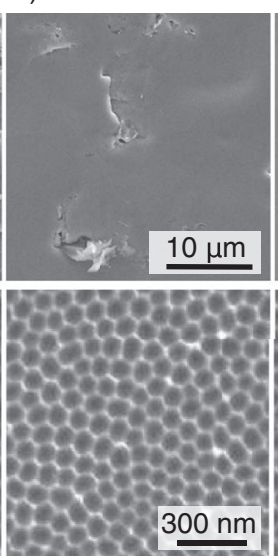

c) EP for $5 \mathrm{~min}$
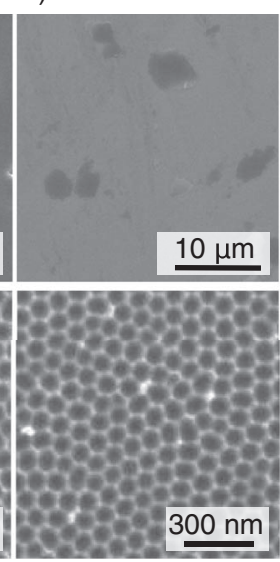

d) EP for $10 \mathrm{~min}$
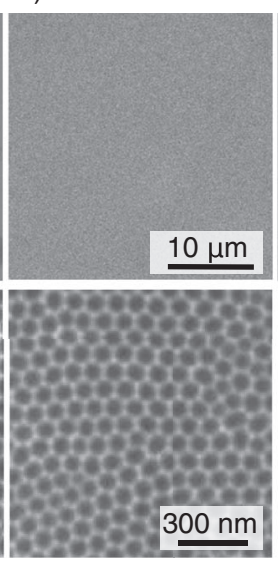

e) EP/AP
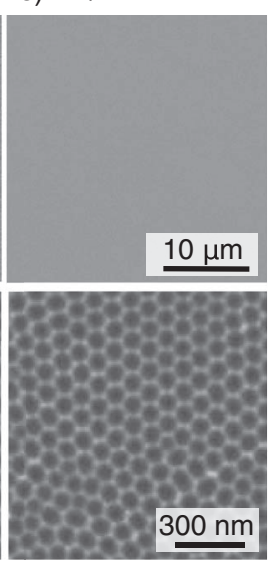

Figure 6. SEM images of the surface before (upper stage) and after (bottom stage) selenic acid anodizing using various pretreated aluminum specimens: a) mechanical polished (MP); b) electropolished (EP) for $1 \mathrm{~min}$, c) $5 \mathrm{~min}$, and d) $10 \mathrm{~min}$; and e) barrier oxide formation and the subsequent selective oxide dissolution (EP/AP). 


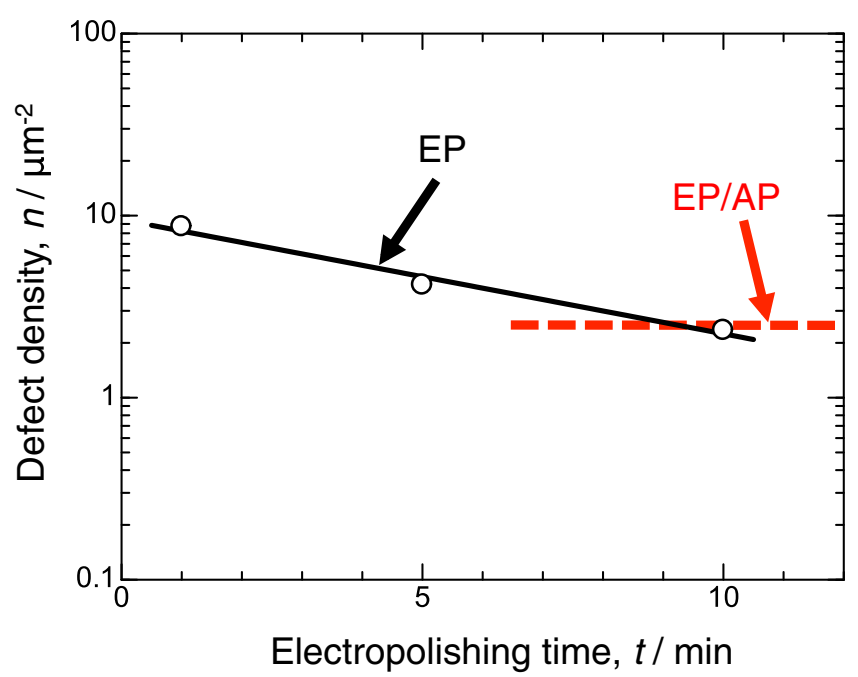

Figure 7. Effect of the electropolishing time before anodizing, t, on the defect density formed on the aluminum dimple array, $\mathrm{n}$, for selenic acid anodizing at the self-ordering voltage of $46 \mathrm{~V}$.

time of $10 \mathrm{~min}$ was measured as $2.3 \mu \mathrm{m}^{-2}$. Therefore, the regularity of the anodic porous alumina is strongly affected by the surface roughness of the aluminum specimen before anodizing and is easily improved by long-term electropolishing as pretreatment. As the EP/AP specimen with the ultra-smooth surface was anodized in selenic acid under the same experimental conditions, the defect density was measured as $2.6 \mu \mathrm{m}^{-2}$, which is almost same value as the electropolished specimen for $10 \mathrm{~min}$ (a dotted line in Fig. 7). Accordingly, the flatness of the aluminum specimen below $1 \mathrm{~nm}$ was not affected by the regularity of the porous alumina during selenic acid anodizing. In summary, the electropolished aluminum surface of approximately $1 \mathrm{~nm}$ in mean roughness is an optimum specimen for the self-ordering of the porous alumina.

Effect of purity of the aluminum specimen on the self-ordering behavior. - To study the effect of the purity of the starting aluminum specimen on the self-ordering behavior, five types of aluminum specimens with different purities (94.5-99.9999 wt\%) were anodized in a 3.0 $\mathrm{M}$ selenic acid solution $(\mathrm{T}=273 \mathrm{~K})$ at $\mathrm{U}=46 \mathrm{~V}$ under vigorous stirring conditions of $\mathrm{v}=563 \mathrm{rpm}$. During selenic acid anodizing using a $94.5 \mathrm{wt} \%$ aluminum specimen, intense oxygen gas evolution was observed from the aluminum specimen, and anodic oxide was not formed on the aluminum specimen according to the SEM observations of the vertical cross section (Figure $8 \mathrm{a}$ ). In this low purity aluminum specimen, copper added as the alloying element formed second phases of metals and metallic compounds, such as $\mathrm{Al}_{2} \mathrm{Cu}$, in the aluminum matrix. ${ }^{56}$ These second phases exposed on the surface led to the preferential anodic dissolution and oxygen gas evolution during selenic acid anodizing under the highest voltage applied. Therefore, selenic acid anodizing and subsequent regularity analysis were carried out using a relatively high purity aluminum specimen with a 99.5-99.9999 wt\% purity. From the SEM observations before selenic acid anodizing, a second phase or metallic compound was confirmed to not be observed in the matrix of these aluminum specimens.

Figures $8 \mathrm{~b}$ through 8e show SEM images of the exposed nanostructured aluminum surface after selenic acid anodizing with aluminum specimens of different purities and selective oxide dissolution. An ordered aluminum dimple array measuring approximately $110 \mathrm{~nm}$ in diameter can be observed on each aluminum surface, although several white defects were observed at the boundary of the hexagonal honeycomb structure. From these SEM images, it seems that the regularity of the dimple array is almost the same, regardless of the purity of the starting aluminum specimen. A change in the defect densities, $n$, with the purity of the aluminum, $p$, during selenic acid anodizing is shown
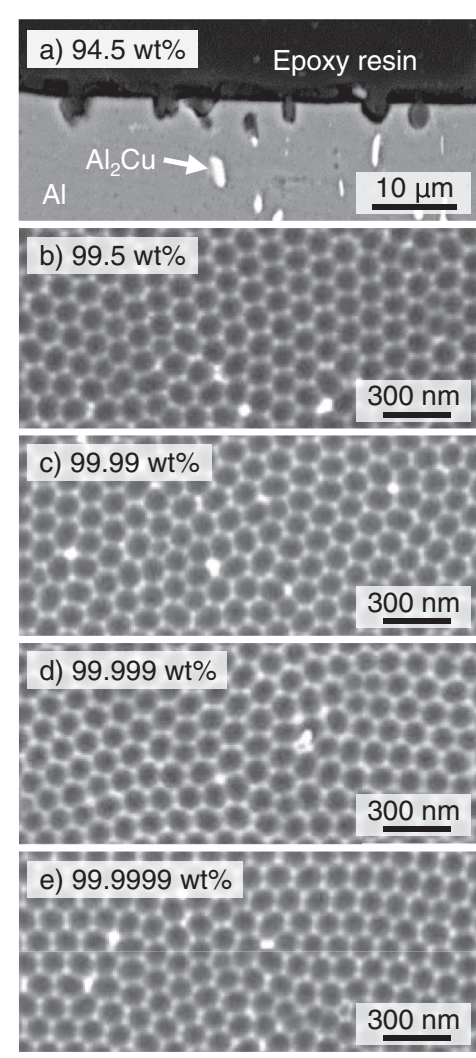

Figure 8. a) SEM image of the cross-section of a $94.5 \mathrm{wt} \%$ aluminum specimen after selenic acid anodizing at $46 \mathrm{~V}$ for $1 \mathrm{~h}$. b)-e) SEM images of the aluminum dimple array fabricated on b) $99.5 \mathrm{wt} \%$, c) $99.99 \mathrm{wt} \%$, d) 99.999 wt $\%$, and e) 99.9999 wt $\%$ aluminum specimens after selenic acid anodizing and subsequent selective oxide dissolution.

in Figure 9. Clearly, the defect densities were measured to be approximately $3.5 \mu \mathrm{m}^{-2}$ for all grades of purity of the aluminum specimens, and the defect densities exhibit a steady value during the selenic acid anodizing under self-ordering conditions. This interesting result is very important for the fabrication of highly ordered porous alumina in the study of fundamental nanofabrication and also industrial applications. Notably, well-ordered porous alumina can be fabricated via anodizing using not only with high purity aluminum but also with low purity aluminum, such as a commercially available industrial grade aluminum, AA1000. Therefore, low-cost fabrication of the ordered

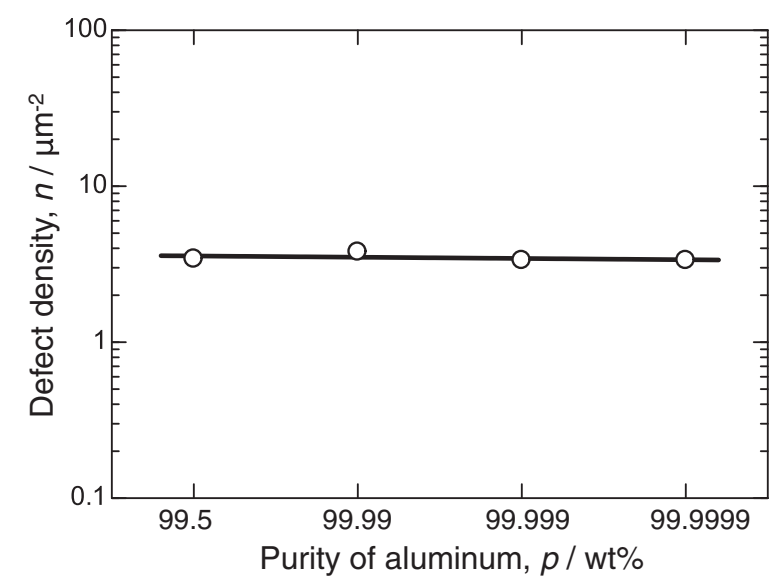

Figure 9. Effect of the purity of aluminum on the defect density formed on the aluminum dimple array, $\mathrm{n}$, for selenic acid anodizing at the self-ordering voltage of $46 \mathrm{~V}$. 


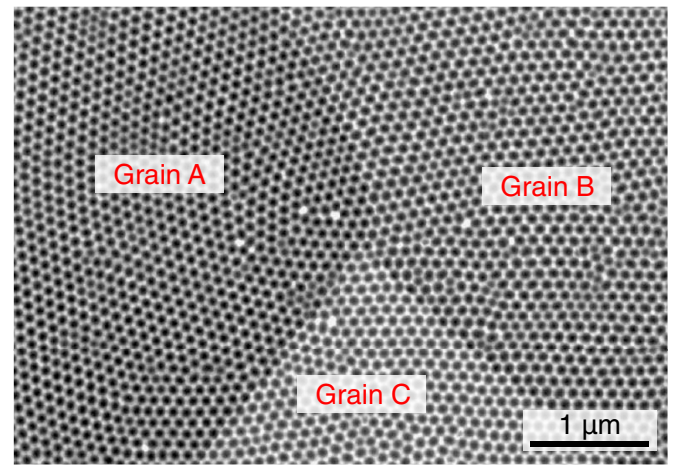

Figure 10. SEM image of the nanostructured aluminum surface at a grain boundary triple junction of the aluminum matrix.

porous alumina can be achieved by anodizing using a low purity aluminum plate without a second phase or a metallic compound in the aluminum matrix.

Figure 10 shows an SEM image of the dimple arrangement formed via selenic acid anodizing at a grain boundary of the aluminum matrix. Here, the observed area was separated by a grain boundary triple junction consisting of three aluminum grains. An ordered aluminum dimple array was also fabricated at a step over the grain boundary, and clearly, disordered or uneven arrangements along the grain boundary could not be observed. During anodizing under the high voltage self-ordering conditions without oxide burning, high metal-oxide interface motion occurs through the combination of ionic migration in the anodic oxide and the stress-driven interface diffusion of metal atoms. ${ }^{57-60}$ Therefore, the same ordering of the porous alumina may occur at a defect in the crystal structure, such as the grain boundary.

Fabrication of self-ordered porous alumina via selenic acid anodizing under optimum conditions. - Self-ordering behaviors of anodic porous alumina fabricated via selenic acid anodizing were investigated under different conditions, such as solution stirring, anodizing time, surface roughness, and purity of the aluminum specimen, through sections Effect of stirring the solution on the oxide burning phenomenon to Effect of purity of the aluminum specimen on the self-ordering behavior. From these experimental results, fabrication of highly ordered porous alumina can be achieved via selenic acid anodizing, in well-stirred selenic acid solution, for long-term periods, using an aluminum specimen with a smooth surface formed by electropolishing, under the highest anodizing voltage. Figure 11 shows the SEM image of the highly ordered aluminum dimple array formed via selenic acid anodizing under the optimum conditions obtained by the present investigation, at $\mathrm{v}=563 \mathrm{rpm}$ and $\mathrm{U}=46 \mathrm{~V}$ for $\mathrm{t}=24 \mathrm{~h}$ using

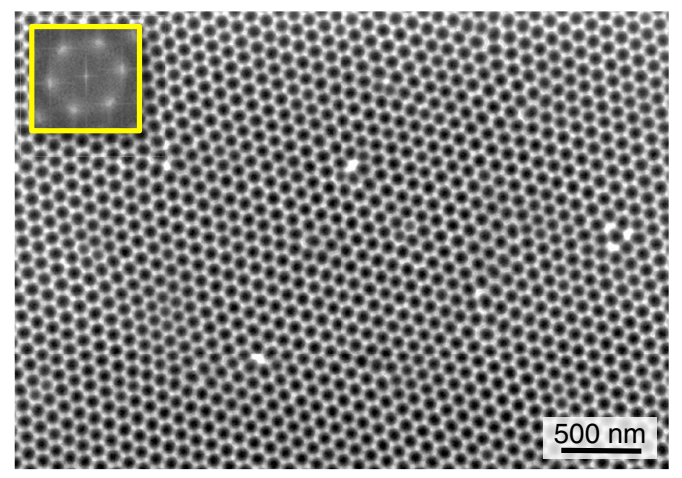

Figure 11. SEM image of the highly ordered aluminum dimple array fabricated via selenic acid anodizing at $46 \mathrm{~V}$ for $24 \mathrm{~h}$ using a $99.999 \mathrm{wt} \%$ aluminum plate electropolished for $10 \mathrm{~min}$. The insert figure shows the FFT image of the ordered nanostructure. a $99.999 \mathrm{wt} \%$ aluminum plate electropolished for $10 \mathrm{~min}$. The ordered dimple array measuring $111 \mathrm{~nm}$ in diameter was distributed, with an ideal dimple arrangement over a wide range of the aluminum surface. An insert figure shows the FFT image of the aluminum dimple array, and a near perfect six-fold symmetric shape was obtained via selenic acid anodizing under the optimum conditions. Such a high regularity of the porous alumina can easily be achieved via simple self-ordered selenic acid anodizing without high-cost processes such as nanoimprinting or hard anodizing. Self-ordered selenic acid anodizing works effectively at a previously unutilized self-ordering voltage. Therefore, the comparison of the growth behavior and the corresponding nanofeatures of the porous alumina formed in selenic and other acid may be useful for understanding the mechanism of porous oxide growth. In addition, the self-ordered behaviors and the optimum conditions obtained in the present investigation will be useful for anodizing in other self-ordered electrolyte solutions such as etidronic acid.

\section{Conclusions}

We demonstrated the self-ordering behavior of anodic porous alumina fabricated via selenic acid anodizing under various operating conditions. The vigorous stirring of the electrolyte solution is very important to remove the Joule heat and avoid oxide burning during anodizing, although excess stirring improves the situation very little. The regularity of the porous alumina is improved as the anodizing time and surface flatness increase. The flatness of the aluminum specimen below $1 \mathrm{~nm}$ did not improve the regularity. In addition, the purity of the aluminum specimen without second phases of metals and metallic compounds is not affected by the regularity of the porous alumina. Considering these experimental results, a highly ordered aluminum dimple array with a cell diameter measuring $111 \mathrm{~nm}$ can be fabricated successfully via selenic acid anodizing under the optimum operating conditions.

\section{Acknowledgments}

This study was conducted at Hokkaido University and was supported by the "Nanotechnology Platform" Program of the Ministry of Education, Culture, Sports, Science, and Technology (MEXT), Japan. The work was supported financially by the Light Metal Educational Foundation, the Japan Society for the Promotion of Science (JSPS) "KAKENHI", and Toyota Physical \& Chemical Research Institute Scholars.

\section{References}

1. J. Martín, M. Martín-González, J. F. Fernández, and O. Caballero-Calero, Nat. Commun., 5, 5130 (2014)

2. T. Yanagishita, M. Masui, N. Ikegawa, and H. Masuda, J. Vac. Sci. Technol. B, 32 021809 (2014)

3. T. Yanagishita, K. Nishio, and H. Masuda, Appl. Phys. Express, 2, 022001 (2009).

4. Y. Chen, A. Santos, Y. Wang, T. Kumeria, C. Wang, J. Li, and D. Losic, Nanoscale, 7, 7770 (2015).

5. S. J. Li, N. Xia, B. Q. Yuan, W. M. Du, Z. F. Sun, and B. B. Zhou, Electrochim. Acta, 159, 234 (2015).

6. A. Yamaguchi, K. Hotta, and N. Teramae, Anal. Chem., 81, 105 (2008)

7. T. Ozel, G. R. Bourret, and C. A. Mirkin, Nat. Nanotechnol., 10, 319 (2015).

8. I. Vrublevsky, A. Jagminas, J. Schreckenbach, and W. A. Goedel, Appl. Surf. Sci., 253, 4680 (2007).

9. J. Li, C. Papadopoulos, J. M. Xu, and M. Moskovits, Appl. Phys. Lett., 75, 367 (1999)

10. W. Lee, K. Schwirn, M. Steinhart, E. Pippel, R. Scholz, and U. Gösele, Nat. Nanotechnol., 3, 234 (2008).

11. S. Z. Kure-Chu, K. Osaka, H. Yashiro, H. Segawa, K. Wada, and S. Inoue, J. Elec trochem. Soc., 162, C24 (2015).

12. T. Masuda, H. Asoh, S. Haraguchi, and S. Ono, Materials, 8, 1350 (2015).

13. T. Kondo, N. Kitagishi, T. Yanagishita, and H. Masuda, Appl. Phys. Express, 8, 062002 (2015).

14. H. Masuda and K. Fukuda, Science, 268, 1466 (1995)

15. W. Lee and S. J. Park, Chem. Rev., 114, 7487 (2014).

16. G. D. Sulka, in Nanostructured materials in electrochemistry, A. Eftekhari, Editor, P. 1, Wiley-VCH, Weinheim (2008)

17. A. P. Li, F. Müller, A. Birner, K. Nielsch, and U. Gösele, J. Appl. Phys., 84, 6023 (1998). 
18. L. Zaraska, W. J. Stępniowski, M. Jaskuła, and G. D. Sulka, Appl. Surf. Sci., 305, 650 (2014).

19. W. J. Stępniowski, D. Forbot, M. Norek, M. Michalska-Domańska, and A. Król, Electrochim. Acta, 133, 57 (2014).

20. W. J. Stępniowski, M. Michalska-Domańska, M. Norek, and T. Czujko, Mater. Lett., 117, 69 (2014).

21. W. Lee, R. Ji, U. Gösele, and K. Nielsch, Nat. Mater, 5, 741 (2006).

22. S. Ono, M. Saito, M. Ishiguro, and H. Asoh, J. Electrochem. Soc., 151, B473 (2004).

23. S. Ono, M. Saito, and H. Asoh, Electrochim. Acta, 51, 827 (2005).

24. A. Zahariev, I. Kanazirski, and A. Girginov, Inorg. Chim. Acta, 361, 1789 (2008)

25. S. Z. Chu, K. Wada, S. Inoue, M. Isogai, Y. Katsuta, and A. Yasumori, J. Electrochem. Soc., 153, B384 (2006).

26. M. Pashchanka and J. J. Schneider, Phys. Chem. Chem. Phys., 15, 7070 (2013).

27. T. Kikuchi, T. Yamamoto, and R. O. Suzuki, Appl. Surf. Sci., 284, 907 (2013).

28. T. Kikuchi, O. Nishinaga, S. Natsui, and R. O. Suzuki, ECS Electrochem. Lett, 3, C25 (2014).

29. T. Kikuchi, T. Yamamoto, S. Natsui, and R. O. Suzuki, Electrochim. Acta, 123, 14 (2014).

30. T. Kikuchi, D. Nakajima, J. Kawashima, S. Natsui, and R. O. Suzuki, Appl. Surf. Sci., 313, 276 (2014).

31. D. Nakajima, T. Kikuchi, J. Kawashima, S. Natsui, and R. O. Suzuki, Appl. Surf. Sci., 321, 364 (2014).

32. T. Kikuchi, O. Nishinaga, D. Nakajima, J. Kawashima, S. Natsui, N. Sakaguchi, and R. O. Suzuki, Sci. Rep., 4, 7411 (2014).

33. D. Nakajima, T. Kikuchi, S. Natsui, and R. O. Suzuki, ECS Electrochem. Lett., 4, H14 (2015).

34. G. Knörnschild, A. A. Poznyak, A. G. Karoza, and A. Mozalev, Surf. Coat. Technol., 275, 17 (2015).

35. T. Kikuchi, S. Nakajima, O. Nishinaga, S. Natsui, and R. O. Suzuki, Curr. Nanosci., 12, 560 (2015).

36. M. Norek, M. Dopierała, and W. J. Stępniowski, J. Electroanal. Chem., 750, 79 (2015).

37. X. Qin, J. Zhang, X. Meng, C. Deng, L. Zhang, G. Ding, H. Zeng, and X. Xu, Appl. Surf. Sci., 328, 459 (2015).

38. T. Kao and Y. Chang, Appl. Surf. Sci., 288, 654 (2014).
39. S. Leung, M. Yu, Q. Lin, K. Kwon, K. Ching, L. Gu, K. Yu, and Z. Fan, Nano Lett., 12, 3682 (2012).

40. X. Chen, D. Yu, L. Gao, X. Zhu, Y. Song, H. Huang, L. Lu, and X. Chen, Mater. Res. Bull., 57, 116 (2014).

41. J. Bellemare, F. Sirois, and D. Ménard, J. Electrochem. Soc., 161, E75 (2014).

42. S. Shingubara, K. Morimoto, H. Sakaue, and T. Takahagi, Electrochem. Solid-State Lett., 7, E15 (2004).

43. O. Nishinaga, T. Kikuchi, S. Natsui, and R. O. Suzuki, Sci. Rep., 3, 2748 (2013).

44. T. Kikuchi, O. Nishinaga, S. Natsui, and R. O. Suzuki, Electrochim. Acta, 137, 728 (2014).

45. T. Kikuchi, O. Nishinaga, S. Natsui, and R. O. Suzuki, Electrochim. Acta, 156, 235 (2015).

46. T. Kikuchi, O. Nishinaga, S. Natsui, and R. O. Suzuki, Appl. Surf. Sci., 341, 19 (2015).

47. A. Takenaga, T. Kikuchi, S. Natsui, and R. O. Suzuki, ECS Solid State Lett., 4, P55 (2015).

48. K. Shimizu, K. Kobayashi, G. E. Thompson, and G. C. Wood, J. Surf. Fin. Soc. Jpn., 42, 645 (1991).

49. I. De Graeve, H. Terryn, and G. E. Thompson, J. Electrochem. Soc., 150, B158 (2003).

50. T. Aerts, I. De Graeve, and H. Terryn, Electrochim. Acta, 54, 270 (2008).

51. F. Li, L. Zhang, and R. M. Metzger, Chem. Mater, 10, 2470 (1998).

52. W. Lee, K. Nielsch, and U. Gösele, Nanotechnology, 18, 475713 (2007).

53. H. Asoh, K. Nishio, M. Nakao, T. Tamamura, and H. Masuda, J. Electrochem. Soc., 148, B152 (2001)

54. T. Kikuchi, Y. Wachi, M. Sakairi, and R. O. Suzuki, Microelectron. Eng., 111, 14 (2013).

55. V. V. Konovalov, G. Zangari, and R. M. Metzger, Chem. Mater, 11, 1949 (1999).

56. T. Kikuchi, Y. Hara, M. Sakairi, T. Yonezawa, A. Yamauchi, and H. Takahashi, Corr. Sci., 52, 2525 (2010).

57. J. E. Houser and K. R. Hebert, Nat. Mater, 8, 415 (2009).

58. K. R. Hebert and J. E. Houser, J. Electrochem. Soc., 156, C275 (2009).

59. K. R. Hebert, S. P. Albu, I. Paramasivam, and P. Schmuki, Nat. Mater, 11, 162 (2012).

60. Ö. Ö. Çapraz, P. Shrotriya, P. Skeldon, G. E. Thompson, and K. R. Hebert, Electrochim. Acta, 167, 404 (2015). 